\title{
Malignant mesothelioma and asbestos exposure in Europe: Evidence of spatial clustering
}

\author{
Ewa Wilk, Małgorzata Krówczyńska \\ Department of Geoinformatics, Cartography and Remote Sensing, Faculty of Geography and Regional \\ Studies, University of Warsaw, Warsaw, Poland
}

\begin{abstract}
Exposure to asbestos causes a wide range of diseases, such as asbestosis, malignant mesothelioma (MM) and other types of cancer. Many European countries have reduced production and use of asbestos and some have banned it altogether. Based on data derived from the World Health Organisation (WHO) Cancer Mortality Database, we investigated whether some regions in Europe could have a higher relative risk of MM incidence than others. The data were compared, including the number of MM deaths per million inhabitants and aged-standardized mortality rates. Applying Moran's $I$ and Getis-Ord Gi statistic on the agedstandardized mortality rates of MM cases assisted the spatial analysis of the occurrence of health events leading to an assessment of the heterogeneity of distribution and cluster detection of MM. We found a statistically significant positive autocorrelation for the male population and also the general population, while there was no statistically significant positive one for the female population. Hotspots of relative risk of developing MM were found in north-
\end{abstract}

Correspondence: Ewa Wilk, Department of Geoinformatics, Cartography and Remote Sensing, Faculty of Geography and Regional Studies, University of Warsaw, Krakowskie Przedmiescie 30, 00-927 Warsaw, Poland.

Tel.: +48.22.5520654 - Fax: +48.22.5521521

E-mail: ewa.wilk@uw.edu.pl

Key words: Asbestos; asbestos exposure; malignant mesothelioma; spatial clustering; public health; spatial analysis; Europe.

Contributions: the authors contributed equally.

Conflict of interests: the authors declare no potential conflict of interests.

See online Appendix for additional data.

Received for publication: 13 October 2020.

Revision received: 24 February 2021.

Accepted for publication: 25 February 2021.

(C) Copyright: the Author(s), 2021

Licensee PAGEPress, Italy

Geospatial Health 2021; 16:951

doi:10.4081/gh.2021.951

This article is distributed under the terms of the Creative Commons Attribution Noncommercial License (CC BY-NC 4.0) which permits any noncommercial use, distribution, and reproduction in any medium, provided the original author(s) and source are credited. western Europe. For the general population, Great Britain and the Netherlands stood out with high levels at the $99 \%$ and $95 \%$ confidence levels, respectively. For the male population, the results were similar, but with addition of risk also in Belgium and Switzerland. However, in many European countries with high asbestos use per capita, the MM incidence was found to still be low. The reasons for this are not yet clear, but part of the problem is certainly due to incomplete data in registers and databases. The latency time can be longer than 40 years and is related to the intensity and time of exposure (occupational, para-occupational and environmental). In Europe, even though peak production occurred in the 1960s and 1970s, a significant decrease in production did not occur until 25 years later, which means that the impact will continue for as late as The mid 2030s.

\section{Introduction}

The term asbestos is applied to a group of minerals that have been widely used in the construction industry over the past century (Hendry, 1965). Physical properties such as strong and indestructible fibres are valuable for creating resilient, heat-resistant building sheets and heat insulation for boilers and furnaces. The global peak of the production of asbestos-containing products occurred in the 1960-1980 period when there were more than 3000 asbestos applications in the national economies (Virta, 2002).

Exposure to airborne asbestos fibres occurs during handling of the material in relation with mining, transport and construction. In addition, there is also exposure during removal and repair of existing asbestos structures, as well as due to deterioration of the material in situ (McDonald et al., 1997). Fibrous shape, such as that shown by fluoro-edenite, eronite and tremolite minerals in various geographical areas, affects the airways when inhaled (Ledda et al., 2018), and the fibres resist natural removal from the lungs as they become embedded in the pulmonary parenchyma (Suzuki \& Yokohama, 1991). They accumulate in the lung tissue throughout life, and their negative impact on health depends on the degree of deep penetration, and the number of fibres retained in the lower parts of the respiratory system (Jamrozik et al., 2011). The inflammatory and cancerous reactions in the pulmonary and pleural parenchyma lead to asbestosis, various forms of lung cancer (especially in smokers), pleural malignant mesothelioma (MM), mild pleural effusion and diffuse pleural thickening (Robinson et al., 2005). However, this process is gradual and overt disease does generally not occur until many years, even decades later (Reid et al., 2014).

Recognizing asbestos exposure as a specific health risk was initially slow. While epidemiological studies were key to understanding the association, laboratory testing of asbestos exposure con- 
tributed to understanding the carcinogenicity process at the cellular level (Murray, 1990; Barrett, 1994). The most important feature determining the ability of the asbestiform fibres to induce tumours lies in their physical dimensions, i.e., a diameter below 3 micrometres and a length of more than 5 micrometres (Donaldson et al., 1993). The number of MM cases depends on the type of asbestos used and increases with the use of crocidolite (McDonald \& McDonald, 1978). The risk is much higher when exposure includes crocidolite or amosite than chrysotile alone (McDonald \& McDonald, 1996). Indeed, crocidolite is considered the most potent fibre type concerning MM pathogenesis (Schneider et al., 2008).

Asbestos dust constitute the direct cause of MM (Carbone \& Bedrossian, 2006; Wagner et al., 1960; Burdorf \& Heederik, 2011). This neoplasm is a malignant, rare and very deadly type of tumour, which typically originates in the mesothelial cells lining the body's serous cavities, mainly the pleura and the peritoneum (Huncharek, 1992; Agudo et al., 2000; Neyens et al., 2017). The International Statistical Classification of Diseases and Related Health Problems (ICD-10) classifies it as malignant neoplasms of mesothelial and soft tissue, which is categorized as C45 when affecting the lungs after asbestos exposure. The intensity of exposure is a relevant factor that determines the duration of latency periods (Bianchi et al., 1997; Mowe et al., 1984). The disease has proven exceptionally resistant to chemotherapy, radiotherapy and surgery. MM has a very aggressive natural history with a median survival of around 9 months (Robinson \& Chahinian, 2002).

The increasing number of deaths from MM from year to year is becoming a serious problem. Safe disposal of asbestos is one of the goals of the World Health Organization (WHO, 2016, 2018), and $\mathrm{WHO}$ and the International Labour Organization (ILO) therefore recommend banning the use of all forms of asbestos as the most effective way to eliminate asbestos-related diseases. Many countries have already introduced total bans on both production and use (WHO, 2018). However, these actions will only bring results in the future. Currently, an important process is to build public awareness of the harmful effects of asbestos on human health and provide adequate medical care. The mortality rates illustrates the differences in levels between individual countries (Mackenbach et al., 2016) and contributes to appropriate action to reduce death due to MM in the future.

In Europe, a significant increase in MM cases was observed in the 1980s and felt to be due to the large use of asbestos during the recovery after World War II (Van der Borre \& Deboosere, 2014). The highest mortality rates due to MM have occurred in highly developed countries such as Great Britain, Italy, Belgium, France, the Netherlands and Sweden (Peto et al., 1999), countries that all have used large amounts of asbestos in industry. Globally, MM is causing nine deaths per million deaths in men but only 1.9 in women, a difference thought to due to the traditionally lower participation of women in industry (Van der Borre \& Deboosere, 2014). However, at the national level, these figures vary considerably.

The geographical distribution of cases and discovering the potential sources of asbestos contamination are vital for limiting MM. Spatial analysis and spatial regression allow capturing the relationship between cases of illness and environmental conditions (Wakefield, 2007). We aimed at comparing the incidence and mortality of MM and assess the heterogeneity in the distribution of cases by the application of spatial statistics for the detection of clusters, outliers and regions with a reduced risk based on agedstandardized mortality rates (ASMR) of MM in 30 countries in Europe during the period 2005-2015.

\section{Materials and methods}

\section{Study area}

An analysis of the spatial distribution of MM was carried out for 30 of the 44 European countries (see online Appendix). The remaining 14 countries were excluded from the study due to lack of complete MM data. The number of deaths caused by MM according to ICD-10 is published by the International Agency for Research on Cancer (IARC). The Cancer Mortality Database contains selected cancer mortality statistics by country extracted from the latest update (June 2019) of WHO's database (IARC, 2020). We used the total number of MM cases registered by ICD-10 under C45 classified by country and gender (IARC, 2020). Even though the data in the database were updated in June 2019, data from some countries are those reported at the end of 2015, while others are from 2017. To unify the approach, we accepted all data reported in the period 2005-2015 for the study.

\section{Statistics}

Spatial disease analysis can be carried out by local and global statistics, where the former examines the existence and distribution of disease clusters, while the latter provides answers to more general questions about clustering, homogeneity of relative risk (RR), and the potential existence of spatial correlation between the RR in different regions. We used global autocorrelation by Moran's I and global Getis-Ord Gi statistics to investigate potential clustering and local Moran' $I$ to determine areas characterized by an increased value of the coefficient.

Tobler's law (1970), according to which the features of neighbouring areas are more similar than remote areas, applies when investigating spatial relationships. The ASMR in the different countries were tested and all calculations were performed for males, females and the general population. The age-standardized rate is a weighted mean of the age-specific rates, where the weights are the proportions of persons in the corresponding age. Calculations with populations mathematically adjusted to have the same age structure is needed when comparing populations with different ages because age has a powerful influence on risk, e.g., of dying from cancer. We used the WHO data as the weighted mean of the age-specific rates; the weights were taken from the population distribution of the standard population and expressed per 100,000 inhabitants (IARC, 2020). When applying this approach to mortality, defined as the number of deaths occurring in a given period in a specified population (IARC, 2020), it becomes ageadjusted mortality ASMR.

Considering the adjusted standardized mortality rate (ASMR), the RR, a set of neighbouring areas becomes a cluster if the RR of disease is high in number of closely located areas, while an outlier is distinguished by a high RR in comparison to a background of neighbouring areas with low RR (NIPH, 2012). In this study, areas are whole countries and Moran's $I$ autocorrelation coefficient was used to measure the correlation between neighbouring observations, calculated with the following formula (Moran, 1950; Li et al., 2007):

$I=\frac{n \sum_{i=1}^{n} \sum_{j=1}^{n} w_{i j}\left(x_{i}-\bar{x}\right)\left(x_{j}-\bar{x}\right)}{\left(\sum_{i=1}^{n} \sum_{j=1}^{n} w_{i j}\right) \sum_{i=0}^{n}\left(x_{i}-\bar{x}\right)^{2}}, i \neq j$ 
where $n$ is the number of countries; $w_{i j}$ the weight matrix of links between $i$ and $j$ (ASMR in country $i$ or $j$ ); $x_{i}$ and $x_{j}$ variables in the $i$ and $j$ spatial units (countries); and $\bar{x}$ the arithmetic mean of the variable for all units. The value of local Moran's $I$ range from +1 (indicating high- high or low-low clusters) through 0 (= a random pattern) to -1 (indicating high-low or low-high outliers) (Wang et al., 2016).

To examine the measure of the level of the mutual grouping of high and low values, the global Getis-Ord Gi statistic was applied (Getis \& Ord, 1992; Ord \& Getis, 1995).

$$
G=\frac{\sum_{i=1}^{n} \sum_{j=1}^{n} w_{i, j} x_{i} x_{j}}{\sum_{i=1}^{n} \sum_{j=1}^{n} x_{i} x_{j}}, i \neq j
$$

where $x_{i}$ and $x_{j}$ are variables in the spatial units $i$ and $j ; w_{i}$ and $w_{j}$ the weight of links between unit $i$ and unit $j$; and $n$ the number of spatial units. The feature that differentiates the research objects is ASMR. Statistical measures of Getis-Ord Gi statistics were used to determine the local pattern indicating points of high MM risk (Ord \& Getis, 1995):

$$
\mathrm{G}_{\mathrm{i}}(\mathrm{d})=\frac{\sum_{j=i}^{n} w_{i j}(d) x_{j}}{\sum_{j=i}^{n} x_{j}}
$$

where $w_{i j}$ is the weight of links between $i$ and $j$ (MM incidence frequency or aggregated number of registered MM cases in country $i$ or $j) ; x_{j}$ the variable in unit $j$; and $d$ the maximum distance within which the clusters are expected to occur. $\mathrm{Gi}(d)$ statistic measures the intensity of the clustering of high or low values (Harris et al., 2017). To identify the statistically significant hotspot and cold spot clusters the local Moran's I statistic was applied (Anselin, 1995):

$$
I_{i}=\frac{n^{2}}{\sum_{i} \sum_{j} i j} x \frac{\left(x_{i}-\bar{x}\right) \sum_{j} w_{i j}\left(x_{j}-\bar{x}\right)}{\sum_{j}\left(x_{i}-\bar{x}\right)^{2}} i \neq j
$$

In the calculation of Moran's $I$ and Getis-Ord Gi as the parameter of the conceptualization of spatial relationships, inverse Euclidean distance was chosen as a function suitable for continuous data modelling. Mines, plants and places where asbestos is used or produced are sources for the release of asbestos fibres into the environment. Airborne fibres continuously move considerable distances from such emission sources.

The European continent is characterized by a large number of countries of various sizes, some of which are islands (Great Britain, Ireland, Iceland and Malta), some of which are far away from the continent. To ensure that each country had no less than 3 neighbours and the outliers did not distort the results, a Spatial Weights Matrix was generated. The threshold distance values used to calculate the weight matrix (Table 1) were determined based on the first statistically significant spatial autocorrelation peak from the designated tool (Incremental Spatial Autocorrelation). Z-score peaks are the values used for functions with distance parameters (Lin \& Lu, 2009). Spatial weight matrices were calculated for men, women and the general population.

In the two examined groups, i.e. the general population and the male population for the distance of $700 \mathrm{~km}$, the first peak of the $Z$ (I) value was recorded. For the calculation of the weight matrix, this distance was used as the threshold value for all calculations performed. For the female population, the highest recorded z-score was 1.35 , also for a distance of $700 \mathrm{~km}$; there was a statistically

\begin{tabular}{|c|c|c|c|c|c|c|c|c|c|}
\hline & \multicolumn{3}{|c|}{ General population } & \multicolumn{3}{|c|}{ Men } & \multicolumn{3}{|c|}{ Women } \\
\hline Distance & Moran's I & Z-score* & $\mathbf{P}$ & Moran's I & Z-score* & $\mathbf{P}$ & Moran's I & Z-score* & $\mathbf{P}$ \\
\hline 200,000 & 0.054 & 0.67 & 0.5031 & 0.058 & 0.68 & 0.4982 & 0.019 & 0.58 & 0.5640 \\
\hline 300,000 & 0.079 & 0.90 & 0.3662 & 0.089 & 0.95 & 0.3426 & 0.011 & 0.60 & 0.5510 \\
\hline 400,000 & 0.189 & 1.49 & 0.1369 & 0.233 & 1.76 & 0.0780 & -0.111 & -0.40 & 0.6858 \\
\hline 500,000 & 0.243 & 1.83 & 0.0667 & 0.282 & 2.08 & 0.0373 & -0.071 & -0.20 & 0.8398 \\
\hline 600,000 & 0.459 & 3.50 & 0.0005 & 0.495 & 3.75 & 0.0002 & 0.102 & 0.99 & 0.3228 \\
\hline 700,000 & 0.427 & 3.95 & 0.0001 & 0.455 & 4.18 & 0.0000 & 0.120 & 1.35 & 0.1767 \\
\hline 800,000 & 0.363 & 3.54 & 0.0004 & 0.389 & 3.77 & 0.0002 & 0.075 & 0.99 & 0.3203 \\
\hline 900,000 & 0.307 & 3.37 & 0.0008 & 0.332 & 3.60 & 0.0003 & 0.062 & 0.97 & 0.3331 \\
\hline $1,000,000$ & 0.275 & 3.25 & 0.0012 & 0.291 & 3.42 & 0.0006 & 0.070 & 1.12 & 0.2638 \\
\hline $1,100,000$ & 0.201 & 2.81 & 0.0050 & 0.223 & 3.06 & 0.0022 & 0.003 & 0.46 & 0.6442 \\
\hline $1,200,000$ & 0.212 & 3.22 & 0.0013 & 0.232 & 3.48 & 0.0005 & 0.009 & 0.59 & 0.5559 \\
\hline $1,300,000$ & 0.176 & 3.29 & 0.0010 & 0.186 & 3.46 & 0.0005 & 0.032 & 1.07 & 0.2861 \\
\hline $1,400,000$ & 0.126 & 2.86 & 0.0042 & 0.134 & 3.01 & 0.0026 & 0.014 & 0.89 & 0.3743 \\
\hline $1,500,000$ & 0.073 & 1.88 & 0.0601 & 0.076 & 1.94 & 0.0530 & 0.005 & 0.70 & 0.4824 \\
\hline $1,600,000$ & 0.021 & 1.15 & 0.2485 & 0.020 & 1.14 & 0.2560 & 0.004 & 0.81 & 0.4184 \\
\hline
\end{tabular}
significant positive autocorrelation for the female population.

Table 1. Weight matrix for the variation of distance.

${ }_{\mathrm{Z} \text {-score }}=\quad Z=\frac{I_{i}-E\left(U_{i}\right)}{\sqrt{\operatorname{VAR}\left(U_{i}\right)}} ; \mathrm{P}<0.05$ is considered significant. 


\section{Source of data}

Spatial data on the territorial division of Europe were obtained from the Natural Earth database in ESRI shapefile format (Natural Earth, 2019). They reflect the territorial division of Europe into countries. Data on the asbestos supply and consumption trends in European countries until 2003 were derived from the U.S. Geological Survey (https://www.usgs.gov/centers/nmic/asbestosstatistics-and-information). Consumption was defined as production plus imports minus exports (Virta, 2006). The relational database, adapted to the requirements of the PostgreSQL database (https://www.postgresql.org/), was designed and developed to provide a geospatial analysis. ArcGIS software, version 10.5 (https://desktop.arcgis.com/en/quick-start-guides/10.5/arcgisdesktop-quick-start-guide.htm) was used for mapping.

\section{Results}

A statistically significant positive autocorrelation of the ASMR was observed for the male population and the general population, but not for the female population. The strongest autocorrelation of ASMR occurred for the male population (Table 2).

Hotspots (Getis-Ord Gi) of the RR for MM were found to be located in the north-western part of Europe. For the general population, they included Great Britain and the Netherlands with confidence levels at $99 \%$ and $95 \%$, respectively. There were no cold spots in any of the study groups (Figure 1).

Cluster and outlier analysis (Moran's $I$ ) with high and low RR values for MM were determined. Countries with high RR of MM incidence surrounded by high RR of MM incidence are shown in Figure 2. Similarly, High-High clusters (hotspots) were observed in north-western Europe for the male population (in Great Britain, Netherlands and Belgium). For the general population, Switzerland was added. Low-Low ASMR of RR rates of develop-

Table 2. Rates of aged-standardized mortality due to malignant mesothelioma rate in Europe.

\begin{tabular}{lcccccc} 
Case group & Moran's I & Var (I) & Z (I) & Getis-Ord Gi & Var (G) & Z (G) \\
General population & 0.457084 & 0.01329 & 4.2631 & 0.0444 & 0.000009 & 3.2815 \\
Female population (F) & 0.140166 & 0.01301 & 1.5310 & 0.0361 & 0.000003 & 0.9603 \\
\hline Male population (M) & 0.486553 & 0.01332 & 4.5133 & 0.0460 & 0.000001 & 3.6602 \\
\hline
\end{tabular}
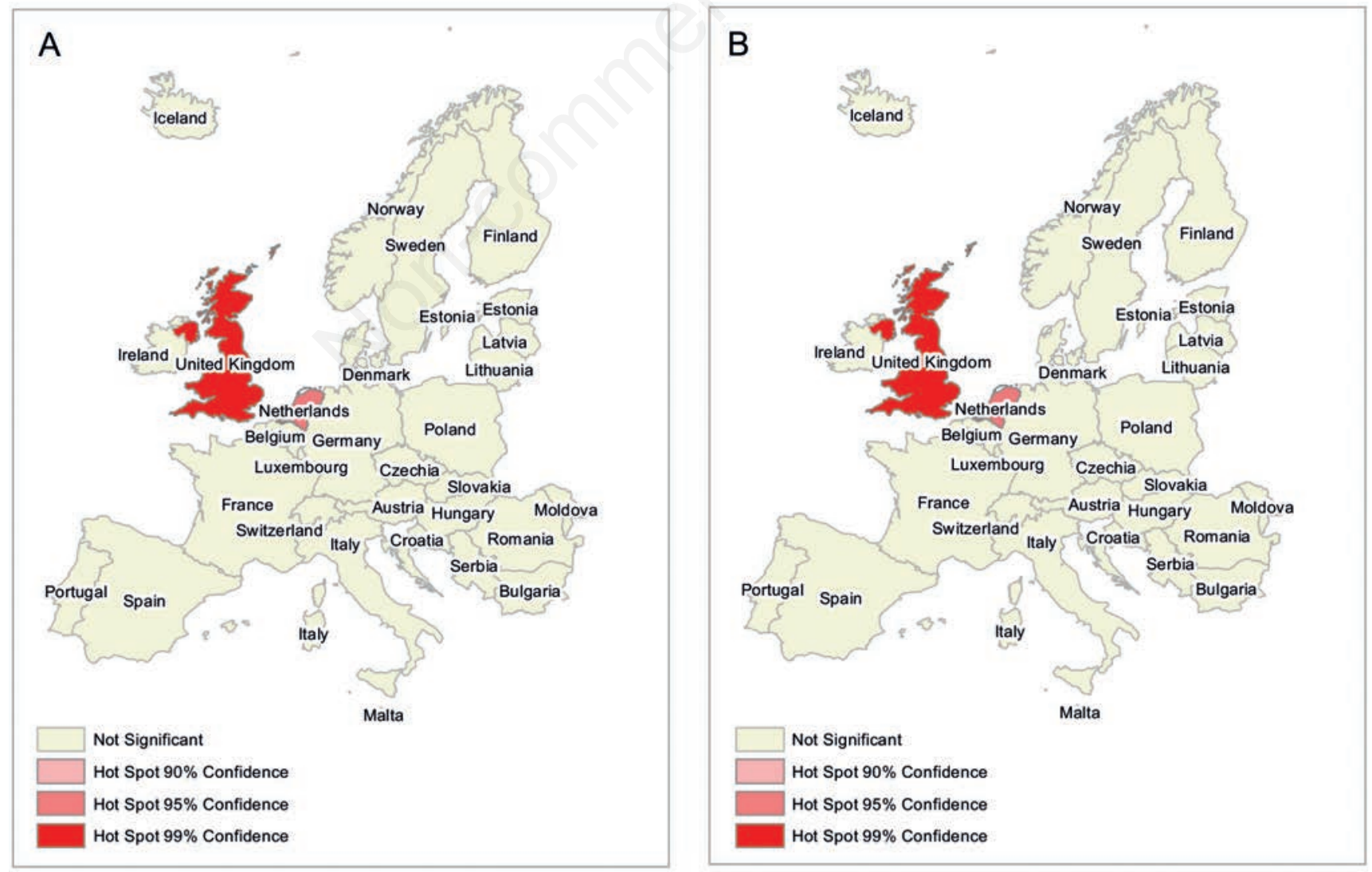

Figure 1. Hotspot analysis of the aged-standardized mortality rates in Europe. A) General population cases; B) male cases. 
ing MM, these were Bulgaria, Romania and Moldova. The figures of the spatial distribution of RR of MM in the male and in the general population are almost identical. Annual asbestos production in Europe has declined since its peak in 1980. As shown in Figure 3, the annual aggregate production of asbestos fell from approximate- ly 160,000 tons in 1980 to approximately 4000 tons by 1999 , where they have remained for the past decade. After Russia, Italy was the second-largest producer of asbestos in Europe for most of the $20^{\text {th }}$ century (Virta, 2006). After World War I, the Balangero Mine near San Vittore opened, and the production of chrysotile
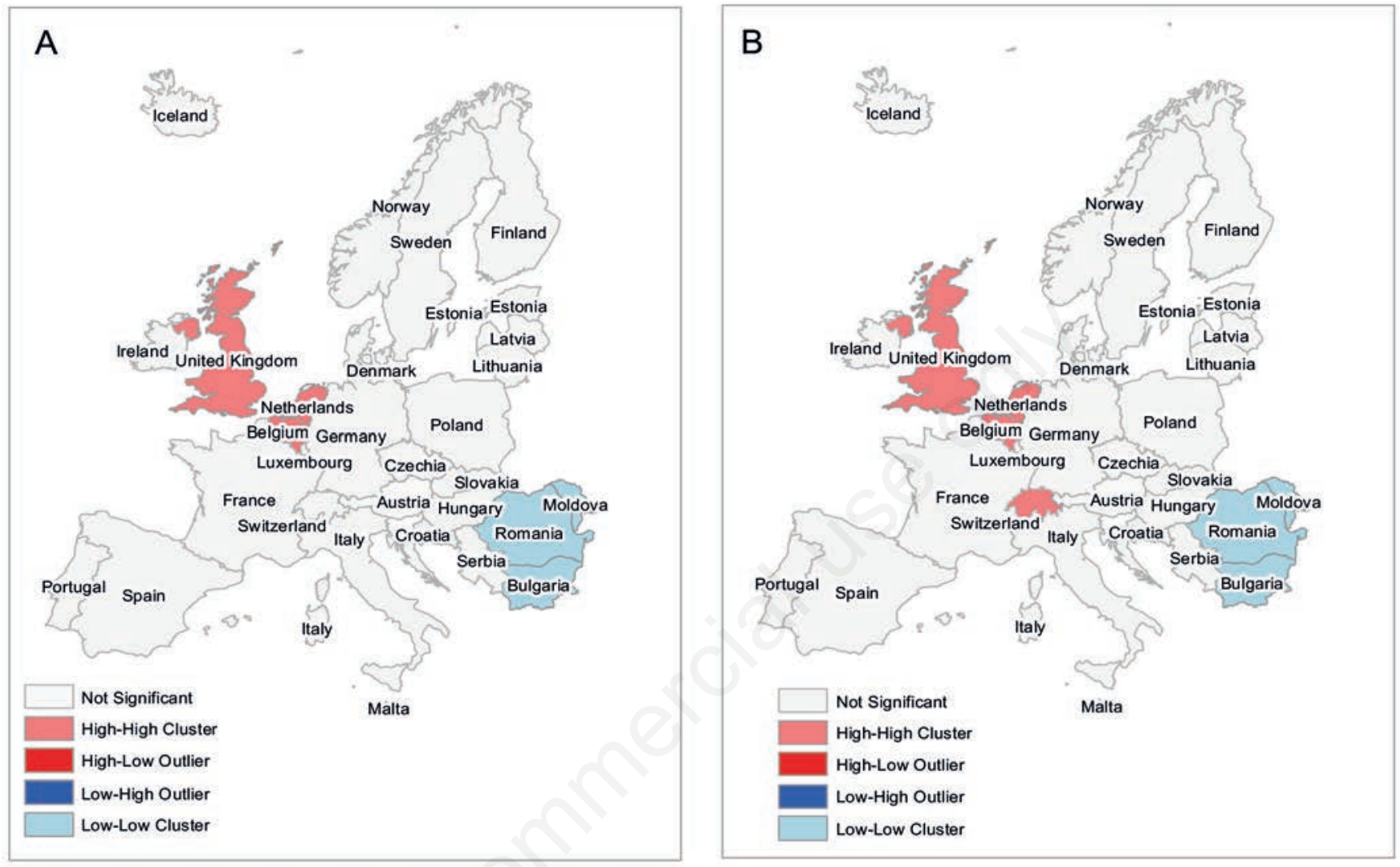

Figure 2. Local autocorrelation of the aged-standardized mortality rates in Europe. A) General population cases; (B) male cases.

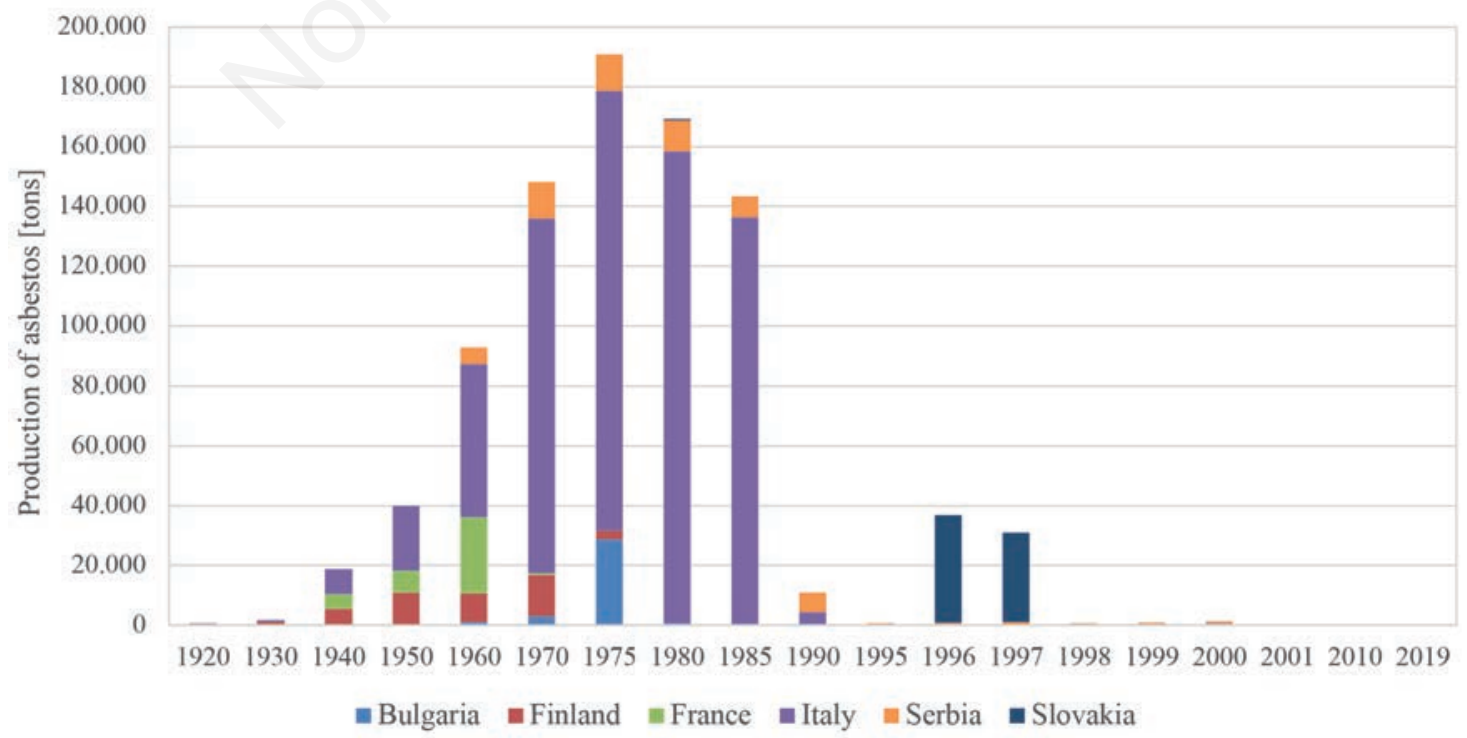

Figure 3. The production of asbestos in Europe (tons). 
started. Around 1968, this mine was upgraded to increase production which peaked at 165,000 tons per year in 1976; however production ceased in 1991 (Virta, 2006). France extracted chrysotile until 1965, when the Eternit Company operated the Canari Mine on the coast of Corsica (Hindry, 2012). Finland was the world's primary source for anthophyllite asbestos (the Paakkila Mine) from about 1919 to 1975 (Virta, 2006), while Slovakia produced small amounts of asbestos until 1999 in its mine near Dobšiná (Sulcova et al., 2001). Bulgaria had asbestos deposits (anthophyllite and tremolite), which were extracted in three underground and four open-pit mines until 1980 (Vangelowa et al., 2015) and Serbia extracted chrysotile in its Korlace and Stragari Mines (Bowles, 1955), which are now closed.

The consumption in analysed European countries has declined since its peak in 1975. As shown in Figure 4, the annual aggregate consumption of asbestos fell from approximately 1.6 million tons in 1975 to approximately 19.0 thousand tons by 2003. An examination of consumption patterns shows a similar pattern across countries that no longer consume asbestos: a stable growth to a peak and then a decline. That decline is a result of introduced legal bans on asbestos use. However, this pattern has occurred at different times for different countries. For example, peaks occurred in the 1960s in Great Britain, in the 1970s in Czechia, France, Spain and Poland, and in the 1980s in Germany and Italy. Although most European countries have banned the production of asbestos-containing products, products containing asbestos are still in use, which has an impact on environmental exposure to asbestos fibres. The comparison of asbestos consumption per capita to the year of the introduction of the asbestos ban (sometimes with exceptions of certain products or uses) is shown in Figure 5.

The consumption in Europe in the period 1920-2003 was concentrated in Germany, Italy, France and Great Britain (Figure 6). Those four countries accounted for $54 \%$ of European asbestos consumption, while eight others - Poland, Spain, Czechia, Belgium, Luxembourg, Slovakia, Romania and Hungary - accounted for an additional 30+\%. The remaining $10 \%$ was spread across 18 countries.
Per capita asbestos use (Figure 7) is an indicator of the MM risk (Krówczyńska \& Wilk, 2018; Tsakane, 1997). The per capita asbestos consumption rate ranged between $0.7 \mathrm{~kg}$ (Serbia) and $38.1 \mathrm{~kg}$ (Slovakia) with a median of $10.7 \mathrm{~kg}$ in Spain, Switzerland and Portugal.

\section{Discussion}

One of the main tasks of public health institutions is to study the spatial diversity in the occurrence of various disease entities to identify environmental factors influencing the increase (or decrease) of health events (such as cases or deaths). If the factors affect a relatively large region, then this increase is recorded in several neighbouring administrative units/countries forming a disease cluster (hotspot). On the other hand, if environmental factors affect only a small area within a single administrative unit of the country, then it is an outlier (NIPH, 2012). The obtained results of this study are presented in the form of hotspot links with areas of asbestos production and use per capita.

Since pleural MM (C45) is directly related to asbestos, the production and use of these minerals in European countries were analysed. Occupational exposure was estimated in individual countries, but there was a lack of research on environmental exposure estimation due to the lack of data on the number of asbestos products still in use. Poland seems to be the only country, where such studies have been carried out (Krówczyńska et al., 2014; Krówczyńska \& Wilk, 2018; Wilk et al., 2019).

In the areas found to be hotspots and local autocorrelations with a high RR of disease, the highest ASMR values in the male population as well as the general population were recorded in Belgium, Great Britain, Netherlands and Switzerland. The ASMR value curve in the study years in all these countries, except Belgium, was found to be slightly sloping. Considering the number of all deaths due to MM recorded in a given year in the male population, the highest number of deaths was recorded in Great

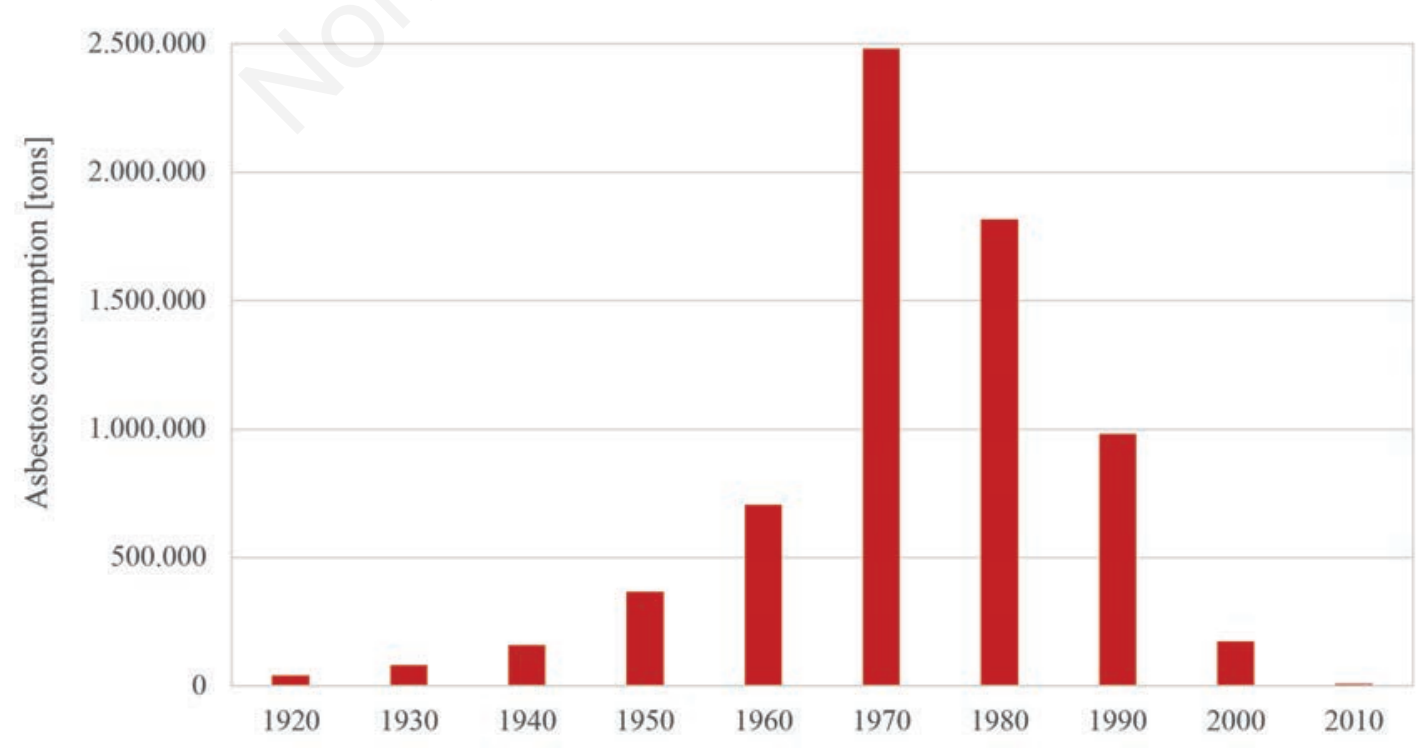

Figure 4. The total asbestos consumption in Europe in the period 1920-2017 (tons). 
Britain, followed by Germany, Italy and France. There is numerous literature references on the incidence of asbestos in workers (Alies-Patin \& Valleron, 1985; Gardner et al., 1986; Peto et al., 1995, 1999; Magnani et al., 2001; Hodgson et al., 2005; Marinaccio et al., 2005; Musti et al., 2009; Hindry, 2012;
Schonfeld et al., 2014; Corfiati et al., 2015; Baur, 2018; HSE, 2019). Great Britain has a long experience of monitoring of MM, which goes back to 1968 (Peto et al., 1995). The annual number of MM deaths has risen rapidly by about 12-fold after 1968 (Hodgson et al., 2005). Projections made by the Health and Safety Executive

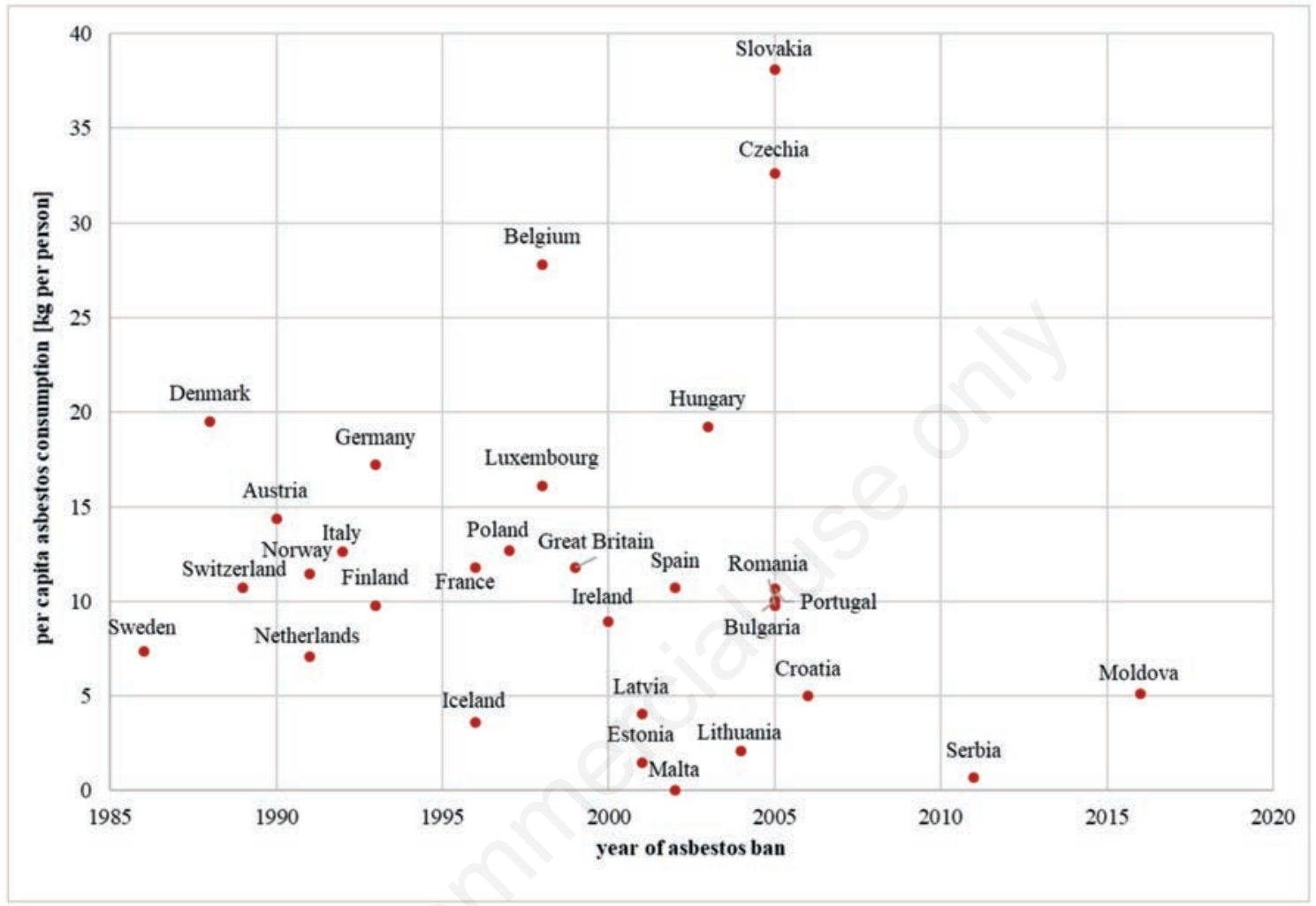

Figure 5. Comparison of the year of asbestos ban with asbestos use in Europe 1920-2020.

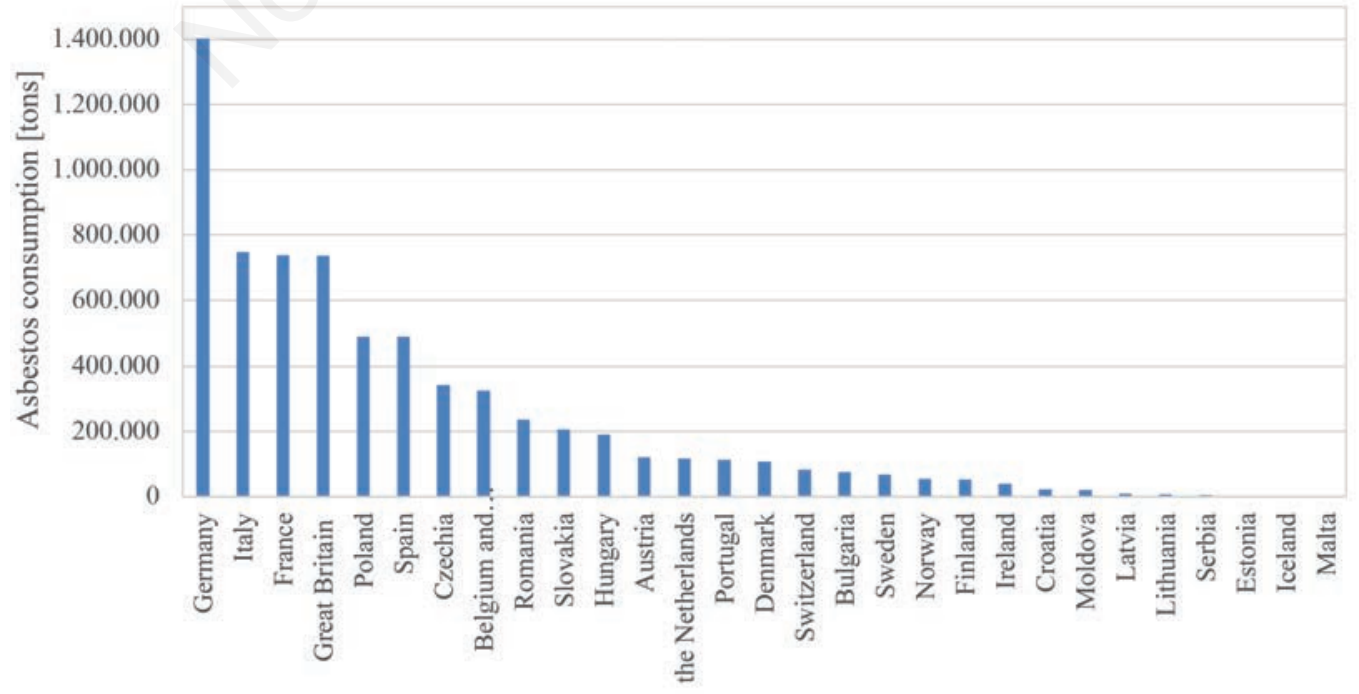

Figure 6. The total asbestos consumption in Europe in the period 1920-2017 per country (tons). 
(HSE), the national regulator for workplace health and safety in Great Britain, suggest that there will be around 2500 deaths per year until the decline, potentially starting around 2020 (HSE, 2019). More than half the number of annual deaths occur in those above 75 years of age (HSE, 2019). A slight reduction has very recently been observed in the male population, while there is a slight increase in the female population (HSE, 2019). The ASMR in Great Britain for the period of 2005-2015 for the male population amounted to 2.9 , and for the general population -1.7 . The mortality rate will depend on the background level and any residual asbestos exposure, e.g. environmental exposure. It is expected that between 1968 and 2050, there will have been approximately 90,000 deaths due to MM in Great Britain, 65,000 of which will occur after 2001 (Hodgson et al., 2005).

Germany is among the countries with high asbestos per capita use (Figure 7A), and with a high number of new MM cases diagnosed (Figure 8). In Germany, the peak of MM burden was predicted to occur by 2020 (Schonfeld et al., 2014), and the undertaken study contains current data emanating from 2015 (IARC, 2020). ASMR in Germany is, however, lower than in other European countries, and it is reported that the total number of asbestos-related deaths is double these figures because of long latency periods leading to a large number of underreported cases (Baur, 2018).

In Italy, the asbestos per capita indicator is much lower than in Germany, but the absolute number of MM cases detected is at a similar level (Figure 8). Estimations on MM incidence based on the age-period-cohort models were similar to those obtained from the asbestos consumption model (Marinaccio et al., 2005).

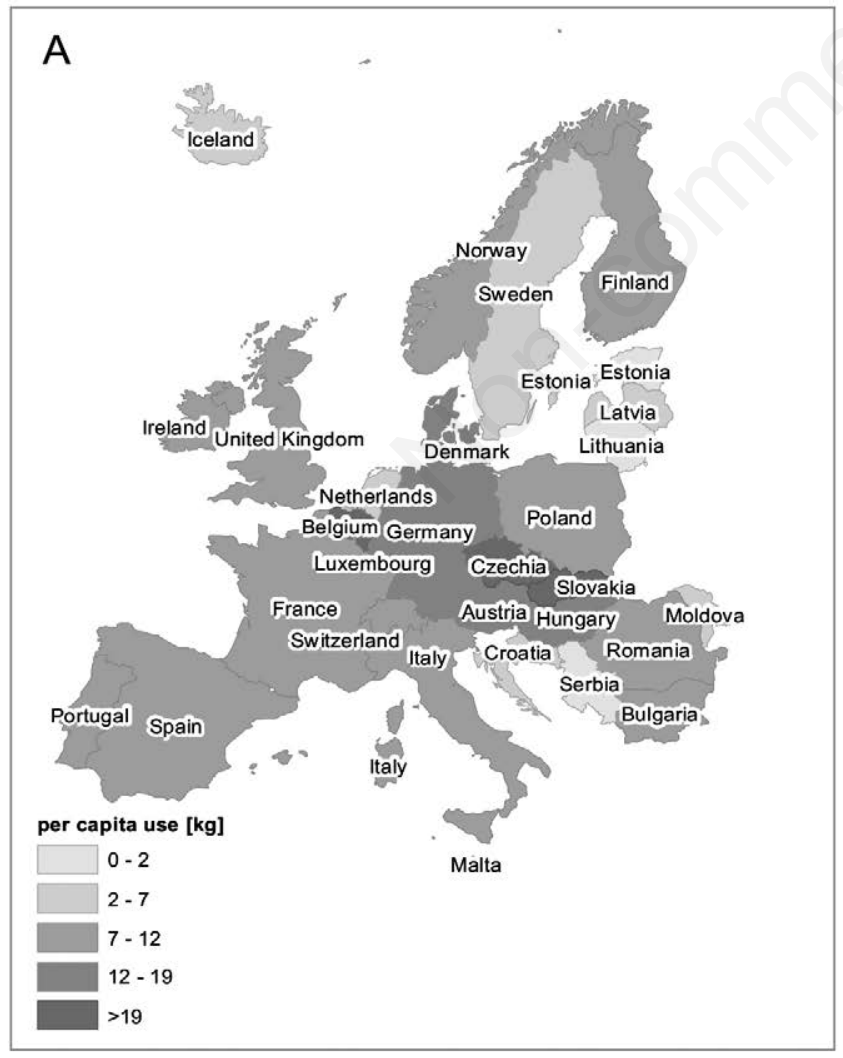

Asbestos cement industry, as well as shipbuilding and repair plants, were indicated as the reasons for MM deaths. Also, a high percentage of environmental exposure cases were found in clusters where asbestos-cement plants were located. Differences in type and source of exposure may also explain the different percentages of cases occurring in the female population (Corfiati et al., 2015). The last survey show that the peak of MM cases is expected in the period 2020-2024. The decrease will be slow: about 26,000 MM cases during the next 20 years (2020-2039), and the epidemic in Italy is far from being concluded despite the national ban implemented in 1992 (Oddone et al., 2020).

Chrysotile asbestos consumption in France peaked in the 1970s (Hindry, 2012) with almost $12 \mathrm{~kg}$ per capita use (Figure 7A). As recent as in 2015, France still presented the fourth-highest number of recognized MM cases in Europe (Figure 8). Data published by the National Health Insurance Fund for Salaried Workers show that occupational diseases due to asbestos exposure have low recognition rates (ANSES, 2016). In the year 2000, the French National Research and Safety Institute estimated that 1 to 2 million workers were potentially exposed to asbestos during repair and maintenance operations, including 900,000 in the building sector (Banaei et al., 2000). A peak MM incidence in France is therefore expected in the period 2030-2040 (Banaei et al., 2000).

In Belgium, the per capita use amounted to almost $28 \mathrm{~kg}$ per person in the period 1920-2003 (Figure 7A). MM deaths were primarily concentrated in geographic areas with proximity to former asbestos industries, with a significant excess in male mortality associated with shipbuilding and asbestos-cement production.

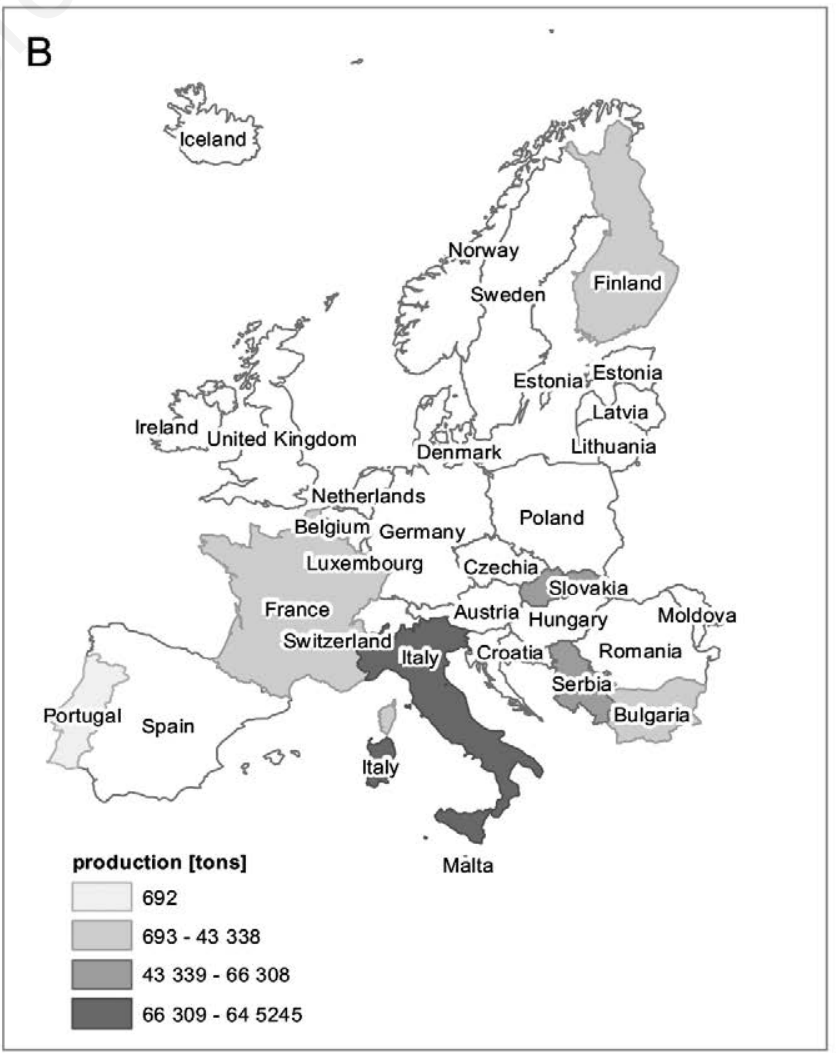

Figure 7. Production and use of asbestos use in Europe 1920-2003. A) Per capita asbestos use in Europe (kg per person); B) Raw asbestos fibres production (tons). 
Belgium became a major international asbestos manufacturer in the early 1900 and, one of Europe's largest asbestos groups, Eternit, started operating in Belgium in 1905 (Van der Borre \& Deboosere, 2014). ASMR for the male population for the period of 2005-2015 amounted to 1.6, and for the general population to 1.0. The MM mortality here has long been underestimated and is nowadays perceived as one of the highest MM mortality rates in the world (Van der Borre \& Deboosere, 2014).

Although the use of asbestos has been concentrated to Great Britain, Germany, Italy and France, it was expected that these countries should be expected to also present the largest number of cases. They do when considering the absolute numbers of death, but when analyzing the ASMR, even if they are difficult to compare, due to the different population sizes in the particular countries at different times, the highest ASMR, i.e. above 1.5 for men and above 1.0 in the general population, was instead recorded for Great Britain, the Netherlands, Switzerland, Belgium, i.e. only Great Britain figures in both groups.

About $90 \%$ of asbestos imported into Switzerland was processed by Eternit factories into asbestos cement products (Schlegel \& Kempf, 1982). Per capita, asbestos use in Switzerland is almost $12 \mathrm{~kg}$ (Figure 7A). Swiss National Accident Insurance Fund reports an increasing number of MM cases from 50 registered in 1999 to 124 in 2013 and undertaking an asbestos prevention program, which aims to protect employees from exposed asbestos fibres (SUVA, 2014). Based on combined data from Britain, France, Germany, Italy, the Netherlands, Switzerland, and Hungary, a peak of MM cases in the male population was expected at about 90,000 cases around 2018 (Peto et al., 1999).

In these countries, associated costs are increasing in parallel with the increase in the number of asbestos-related diseases (Tompa et al., 2017). The increase in these costs in the years 20092012 is very significant (Baur, 2018) since as much as $80 \%$ of these costs may be those related to pensions and rehabilitation, while less than $20 \%$ goes to health care for early detection of ill- nesses and healthcare. In designated high-risk areas, i.e. Great Britain, the Netherlands, Belgium and Switzerland, significant funds are allocated to MM, but we do not know in what proportion they are divided into pensions, compensation, rehabilitation, early diagnosis, detection and treatment, therefore it cannot be concluded that health services need to be improved to reduce the number of MM deaths.

There was no direct correlation between the amount of asbestos used for per capita production and the areas of increased relative disease risk. One reason may be the latency period. The process of disease causation and inhalation of asbestos fibres is still unclear (Pott et al., 1989) in the context of the exposure period in occupation, industry and the environment. This is due to lack of historical measurements of fibre concentrations, which makes it difficult to study the possible relationship between exposure levels and delayed disease. Besides, the type of asbestos used, periods of employment, life expectancy, potential misdiagnosis, as well as differences in asbestos susceptibility affect the latency period (Bianchi \& Bianchi, 2007).

The results of the research indicate that the periods between the first exposure to asbestos and the diagnosis of MM are 20-30 years. However, studies conducted on a large number of cases indicate that, in general, latency periods are longer and have a wide range of variability. Based on a study of Davenport Naval Dockyards employees in the UK diagnosed with MM, the average latency time was 48.5 years (Hilliard et al., 2003). In Italy, it is on average 48 years with a median of 51 years (Bianchi \& Bianchi, 2007); however, a shorter latency period was observed among those exposed at work (43 years) compared to those exposed in environmental and para-occupational exposure (51 years). Increasing latency from year to year may be due to some reduction in the intensity of asbestos exposure in most workplaces in the period before asbestos was banned. The latency period in environmental exposure, as shown by the results of a small sample of cases (98), is about 5 years longer than in domestic exposure

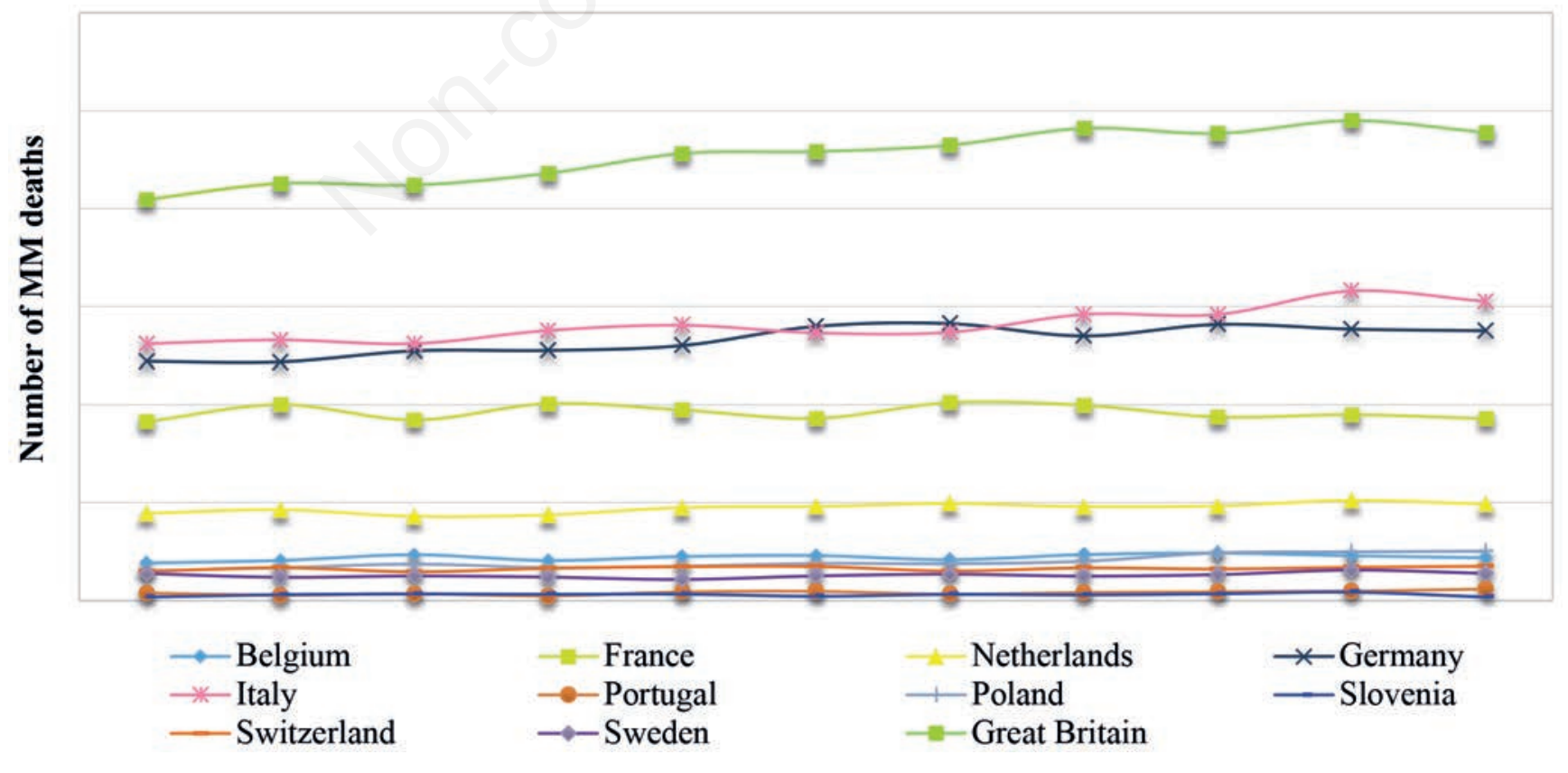

Figure 8. The number of deaths due to malignant mesothelioma (MM) in various European countries in the period 2005-2015. Data from IARC, 2020. 
(Marinaccio et al., 2007).

Areas with an increased relative risk of MM, i.e. in Great Britain (peak production in the 1960s), the Netherlands (peak production in the mid-1970s), Belgium (peak production in the mid1970s), Switzerland (peak production in the 1980s), should occur at different times. However, the collected data show that the number of deaths and ASMR values remains almost constant. One wonders if this is because according to the calculated average latency time of 48 years for Great Britain (Hilliard et al., 2003), the maximum values in the number of deaths per MM should be expected in 2008 (according to WHO databases, the maximum number was denoted for 2009). Assuming this period to be 45 years in the Netherlands and Belgium the highest number of MM cases should be expected in 2020, and in Switzerland in 2025. The ASMR curve in the analysed period in European countries is starting to fall slightly, except in Belgium. This can be influenced by the time elapsed from the peak of the production to its termination. The time from peak asbestos consumption to a $75 \%$ decrease in production in Great Britain was 25 years, in the Netherlands less than 10 years, in Belgium less than 20 years, and in Switzerland 5 years (Allen et al., 2018). By shifting production peaks and decreasing production, we obtain the time from which we should start counting the latency period falls around 1985, in most countries and in Belgium in 1990, which means that similar levels of incidence can be expected to be around 2030-35.

Even though asbestos is a major risk factor, the combination of smoking and asbestos exposure may lead to an increase in the risk of certain types of lung cancers. The review of undertaken studies made by Lee (2001) shows that exposure to asbestos increases the risk of lung cancer in non-smokers and that there is a joint relationship between asbestos and smoking resulting in a multiplying effect. However, because asbestos and smoking are both parts of the carcinogenic process, it has been pointed out to be very difficult to accurately calculate the contribution of asbestos to lung cancers occurring in asbestos-exposed smokers (van Zandwijk et al., 2020). Klebe et al. (2020) have pointed out that asbestos and smoking are inseparable agents at the biological level in the individual case to cause asbestos-related diseases. The increasing relative risk of lung cancer among non-smokers due to asbestos exposure without associated asbestosis was surveyed by Markowitz et al. (2013). The survey has concluded that asbestosis increases the risk of lung cancer and, when considered together with smoking, has an additive effect. The conducted research has shown that the increased risk from smoking varies by the number of cigarettes smoked, duration of smoking, inhalation, and product smoked. Also, the increase of asbestos exposure depends not only on the extent and duration of exposure but also on the type of asbestos and the nature of exposure, i.e. occupational or environmental (Lee, 2001).

Pleural MM (C45) may be also influenced by genetic factors; based on epidemiological analysis of the inhabitants of Turkish villages in Cappadocia, the mortality rate due to this cancer is $50 \%$. Erionite, a fibrous volcanic rock, is used there for building construction. Despite the similar exposure of all inhabitants of the region, the incidence of MM was observed with different frequency in individual families, which suggests another influence, possibly genetic predisposition, apart from the environmental factor (Carbone et al., 2007). MM is also detected in people who have previously received treatment with ionizing radiation during radiotherapy, and these changes develop approximately 20 years after the cessation of irradiation. The cause of pleural MM (C45) can also be caused by prolonged pleural inflammation or the influence of chemical agents (Yang et al., 2008). Therefore, it is difficult to clearly define the influence of the agents that case MM, although asbestos remains the main risk factor.

Unfortunately, detailed data in some national and world databases on the incidence and mortality of MM are incomplete or unavailable. This is a serious limitation as it does not allow sufficient knowledge and risk perception. In the short term, it is expected that the number of cases related to environmental exposure will increase, but without access to reliable registers of places of use of asbestos products, it will be difficult to document, test and predict.

The amount of asbestos used per person in the countries analysed with a potentially higher RR of disease, which is $11.8 \mathrm{~kg}$ per person in Great Britain, $27.8 \mathrm{~kg}$ in Belgium 7, $1 \mathrm{~kg}$, in The Netherlands and $10.7 \mathrm{~kg}$ in Switzerland. However, these data do not correspond to the number of cases per million inhabitants, which is 37 for Great Britain, 18 for The Netherlands, 12 for Belgium and 9 for Switzerland (IARC, 2020). In the case of The Netherlands and Switzerland, it could be influenced by the very quick time of introduction of the restriction on production. The published literature on the subject also give this kind of data for other countries (McElvenny et al., 2005).

Research undertaken by Gilham et al. (2018) has shown that the average lifetime MM risk from environmental asbestos exposure in the UK is around 1 in 10,000. The risk is related to the exposed asbestos worker subgroup and possibly higher also in polluted buildings. Further data are needed to establish whether asbestos still present in buildings poses a risk to people living there, and whether asbestos environmental exposure mainly occurs during childhood or after entry into work. It was pointed out that similar studies are needed in other countries to estimate the ongoing environmental and occupational MM risks worldwide, including the contribution of chrysotile. The possible solution to gauge the asbestos environmental exposure would be to estimate the geographical distribution of asbestos products still in use (Krówczyńska et al., 2020).

\section{Conclusions}

Asbestos is a major risk factor of MM, a malignancy risk which increases when combined with smoking and radiation exposure; it could also be influenced by genetic predispositions. There is a clear connection with production and use of the different asbestos minerals but we need more data on the actual state of the art as far as asbestos products usage is considered to predict risks and improve understanding of the problem.

\section{References}

Agudo A, Gonzalez CA, Bleda MJ, Ramirez J, Hernandez S, Lopez F, Calleja A, Panades R, Turuguet D, Escoalr A, 2000. Occupation and risks of malignant pleural mesothelioma: a case-control study in Spain. Am J Ind Med 37:159-68.

Alies-Patin AM, Valleron AJ, 1985. Mortality of workers in a French asbestos cement factory 1940-82. Br J Ind Med 42:219-25.

Allen LP, Baez J, Stern MEC, Takahashi K, George F, 2018. Trends and the economic effect of asbestos bans and decline in asbestos consumption and production worldwide. Int J Environ Res Public 
Health 16:15.

Anselin L, 1995. Local indicators of spatial association - LISA. Geogr Anal 27:93-115.

ANSES, 2016. French Agency for Food, Environmental and Occupational Health \& Safety. Asbestos. Presentation, health effects, exposure and regulatory framework. Available from: https://www.anses.fr/en/content/asbestos Accessed: 3 January 2020.

Banaei A, Auvert B, Goldberg M, Gueguen A, Luce D, Goldberg S, 2000. Future trends in mortality of French men from mesothelioma. Occup Environ Med 57:488-94.

Barrett JC, 1994. Cellular and molecular mechanisms of asbestos carcinogenicity: implications for biopersistence. Environ Health Perspect 102:19-23.

Baur X, 2018. Asbestos-related disorders in Germany: background, politics, incidence, diagnostics and compensation. Int J Environ Res Public Health 15:143.

Bianchi C, Bianchi T, 2007. Malignant mesothelioma: global incidence and relationship with asbestos. Ind Health 45:379-87.

Bianchi C, Giarelli L, Grandi G, Brollo A, Ramani L, Zuch C, 1997. Latency periods in asbestos-related mesothelioma of the pleura. Eur J Cancer Prev 6:162-6.

Bowles O, 1955. The asbestos industry. United States Government Printing Office, Washington, pp. 48-49.

Burdorf A, Heederik D, 2011. Applying quality criteria to exposure in asbestos epidemiology increases the estimated risk. Ann Occup Hyg 55:565-8.

Carbone M, Bedrossian CW, 2006. The pathogenesis of mesothelioma. Semin Diagn Pathol 23:56-60.

Carbone M, Emri S, Dogan AU, Steele I, Tuncer M, Pass HI, Baris YI, 2007. A mesothelioma epidemic in Cappadocia: scientific developments and unexpected social outcomes. Nat Rev Cancer 7:147-54.

Corfiati M, Scarselli A, Binazzi A, Di Marzio D, Verardo M, 2015. Epidemiological patterns of asbestos exposure and spatial clusters of incident cases of malignant mesothelioma from the Italian national registry. BMC Cancer 15:286.

Donaldson K, Brown RC, Brown GM, 1993. Respirable industrial fibres: mechanisms of pathogenicity. Thorax 48:390-5.

Gardner MJ, Winter PD, Bannett B, Powell CA, 1986. Follow-up study of workers manufacturing chrysotile asbestos cement products. $\mathrm{Br}$ $\mathrm{J}$ Ind Med 43:726-32.

Getis A, Ord JK, 1992. The analysis of spatial association by use of distance statistics. Geogr Anal 24:189-206.

Gilham C, Rake C, Hodgson J, Darnton A, Burdett G, Peto Wild J, Newton M, Nicholson AG, Davidson L, Shires M, Treasure T, Peto J, 2018. TIPS Collaboration. Past and current asbestos exposure and future mesothelioma risks in Britain: the Inhaled Particles Study (TIPS). Int J Epidemiol 47:1745-56.

Harris NL, Goldman E, Gabris C, Nordling J, Minnemeyer S, Ansari S, Lippmann M, Bennett L, Raad M, Hansen M, 2017. Using spatial statistics to identify emerging hot spots of forest loss. Environ Res Lett 12:024012.

Hendry N, 1965. The geology, occurrences, and major uses of asbestos. Ann N Y Acad Sci 132:12-21.

Hilliard AK, Lovett JK, McGavin CR, 2003. The rise and fall in incidence of malignant mesothelioma from a British naval dockyard, 1979-1999. Occup Med 53:209-12.

Hindry M, 2012. Eternit in France. Available from: http://www.ibasecretariat.org/eternit-great-asbestos-trial-chap-15.pdf Accessed: 3 January 2020.

Hodgson JT, McElvenny DM, Darnton AJ, Price MJ, Peto J, 2005. The expected burden of mesothelioma mortality in Great Britain from 2002 to 2050. Br J Cancer 92:587-93.

HSE, 2019. Mesothelioma statistics for Great Britain. Available from: https://www.hse.gov.uk/statistics/causdis/mesothelioma/mesothelioma.pdf Accessed: 3 January 2020.

Huncharek M, 1992. Changing risk groups for malignant mesothelioma. Cancer 69:2704-11.

IARC, 2020. International Agency for Research on Cancer World Health Organization. Available from: http://www-dep.iarc.fr/ WHOdb/WHOdb.htm Accessed: 6 January, 2020.

Jamrozik E, de Klerk N, Musk AW, 2011. Asbestos-related disease. Intern Med J 41:372-80.

Klebe S, Leigh J, Henderson DW, Nurminen M, 2020. Asbestos, smoking and lung cancer: an update. Int J Environ Res Public Health 17:258.

Krówczyńska M, Raczko E, Staniszewska N, Wilk E, 2020. Asbestoscement roofing identification using remote sensing and convolutional neural networks (CNNs). Remote Sens 12:408.

Krówczyńska M, Wilk E, 2018. Asbestos exposure and the mesothelioma incidence in Poland. Int $\mathrm{J}$ Environ Res Public Health 15:1741.

Krówczyńska M, Wilk E, Zagajewski B, 2014. The electronic spatial information system-tools for the monitoring of asbestos in Poland. Misc Geogr 18:59-64.

Ledda C, Senia P, Rapisarda V, 2018. Biomarkers for early diagnosis and prognosis of malignant pleural mesothelioma: the quest goes on. Cancers 10:203.

Lee PN, 2001. Relation between exposure to asbestos and smoking jointly and the risk of lung cancer. Occup Environ Med 58:145-53.

Li H, Calder CA, Cressie N, 2007. Beyond Moran's I: testing for spatial dependence based on the spatial autoregressive model. Geogr Anal 39:357-75.

Lin S, Lu Y, 2009. The spatial patterns of adverse health effects of ozone pollution on childhood respiratory diseases in urban Houston. Ann GIS 15:127-40.

Mackenbach JP, Martikainen P, Menvielle G, de Gelder R, 2016. The arithmetic of reducing relative and absolute inequalities in health: a theoretical analysis illustrated with European mortality data. J Epidemiol Community Health 70:730-6.

Magnani C, Dalmasso P, Biggeri A, Ivaldi C, Mirabelli D, 2001. Increased risk of malignant mesothelioma of the pleura after residential or domestic exposure to asbestos: a case control study in Casale Monferrato, Italy. Environ Health Perspect 9:915-8.

Marinaccio A, Binazzi A, Cauzillo G, Cavone D, Zotti RD, Ferrante P, Gennaro V, Gorini G, Menegozzo M, Mensi C, Merler E, Mirabelli D, Montanaro F, Musti M, Pannelli F, Romanelli A, Scarselli A, Tumino R, 2007. Italian Mesothelioma Register (ReNaM) Working Group. Analysis of latency time and its determinants in asbestos related malignant mesothelioma cases of the Italian register. Eur J Cancer 43:2722-8.

Marinaccio A, Montanaro F, Mastrantonio M, Uccelli R, Altavista P, Nesti M, Costantini AS, Gorini G, 2005. Predictions of mortality from pleural mesothelioma in Italy: a model based on asbestos consumption figures supports results from age-period-cohort models. Int J Cancer 115:142-7.

Markowitz SB, Levin SM, Miller A, Morabia A, 2013. Asbestos, asbestosis, smoking, and lung cancer. New findings from the North American insulator cohort. Am. J. Respir. Crit Care Med 188:90-6.

McDonald AD, Case BW, Churg A, Dufresne A, Gibbs GW, Sébastien P, McDonald JC, 1997. Mesothelioma in Quebec chrysotile miners 
and millers: epidemiology and aetiology. Ann Occup Hyg 41:70719.

McDonald AD, McDonald JC, 1978. Mesothelioma after crocidolite exposure during gas mask manufacture. Environ Res 17:340-6.

McDonald JC, McDonald AD, 1996. The epidemiology of mesothelioma in historical context. Eur Respir J 9:1932-42.

McElvenny DM, Darnton AJ, Price MJ, Hodgson JT, 2005. Mesothelioma mortality in Great Britain from 1968 to 2001. Occup Med 55:79-87.

Moran PAP, 1950. Notes on continuous stochastic phenomena. Biometrika 37:17-23.

Mowe G, Gylseth B, Hartveit F, Skaug V, 1984. Occupational asbestos exposure, lung-fiber concentration and latency time in malignant mesothelioma. Scand J Work Environ Health 10:293-8.

Murray R, 1990. Asbestos: a chronology of its origins and health effects. Br J Ind Med 47:361-5.

Musti M, Pollice A, Cavone D, Dragonieri S, Bilancia M, 2009. The relationship between mesothelioma and an asbestos cement plant environmental risk: a spatial case-control study in the city of Bari (Italy). Int Arch Occup Environ Health 82:489-97.

Natural Earth, 2019. Natural Earth data. Available from: https://www.naturalearthdata.com Accessed: 10 October 2019.

Neyens T, Lawson A, Kirby R, Nuyts V, Watjou K, Aregay M, Carroll R, Nawrot T, Faes CH, 2017. Disease mapping of zero-excessive mesothelioma data in Flanders. Ann Epidemiol 27:59-66.

NIPH, 2012. National Institute of Public Health - National Institute of Hygiene. Description of the methods and interpretation of results presented in the atlas of mortality of Poland population 2012-2014. Available from: http://atlas.pzh.gov.pl/2 /Metody.pdf Accessed: 6 January, 2020.

Oddone E, Bollob J, Nava CR, Bugani M, Consonni D, Marinaccio A, Magnani C, Barone-Adesi F, 2020. Predictions of mortality from pleural mesothelioma in Italy after the ban of asbestos use. Int J Environ Res Public Health 17:607.

Ord JK, Getis A, 1995. Local spatial autocorrelation statistics: distributional issues and an application. Geogr Anal 27:286-306.

Peto J, Decarli A, La Vecchia C, Levi F, Negri E, 1999. The European mesothelioma epidemic. Br J Cancer 79:666-72.

Peto J, Hodgson JT, Matthews FE, Jones JR, 1995. Continuing increase in mesothelioma mortality in Britain. Lancet 345:535-9.

Pott F, Roller M, Ziem U, Reiffer FJ, Bellmann B, Rosenbruch M, Huth F, 1989. Carcinogenicity studies on natural and man-made fibres with the intraperitoneal test in rats. IARC Sci Publ 90:173-9.

Reid A, de Klerk NH, Magnani C, Ferrante D, Musk AW, Merler E, 2014. Mesothelioma risk after 40 years since first exposure to asbestos: a pooled analysis. Thorax 69:843-50.

Robinson B, Chahinian A, 2002. Mesothelioma, 1st ed. Martin Dunitz; CRC Press, London, UK.

Robinson BW, Musk AW, Lake RA, 2005. Malignant mesothelioma. Lancet 366:397-408.

Schlegel H, Kempf E, 1982. Mesotheliome nach beruflichem Asbestkontakt. Soz Präventivmed 27:220-2.

Schneider F, Sporn TA, Roggli VL, 2008. Crocidolite and mesothelioma. Ultrastruct Pathol 32:171-7.

Schonfeld SJ, McCormack V, Rutherford MJ, Schutz J, 2014. Regional variations in German mesothelioma mortality rates: 2000-2010. Cancer Causes Control 25:615-24.
Sulcova M, Krcmery V, Pleko I, Kakoova B, 2001. The Slovakian asbestos experience: use, health effects and preventive measures. Available from: http://www.ibasecretariat.org/ eas_ms_slovakia. php Accessed: 3 January 2020.

SUVA, 2014. Annual Report 2014. Available from: https://www. suva.ch/en/material/Documentations/geschaeftsbericht-2014kurzversion Accessed: 3 January 2020.

Suzuki Y, Kohyama N, 1991. Translocation of inhaled asbestos fibres from the lung to other tissues. Am J Ind Med 19:701-4.

Tobler W, 1970. Computer movie simulating urban growth in the Detroit Region. Econ Geogr 46:234-40.

Tompa E, Kalcevich C, McLeod C, Lebeau M, Song C, McLeod K, Kim J, Demers PA, 2017. The economic burden of lung cancer and mesothelioma due to occupational and para-occupational asbestos exposure. Occup Environ Med 74:816-22.

Tsakane A, 1997. Asbestos, asbestosis and cancer: the Helsinki criteria for diagnosis and attribution. Scand J Work Environ Health 23:311-6.

Van der Borre L, Deboosere P, 2014. Asbestos in Belgium: an underestimated health risk. The evolution of mesothelioma mortality rates (1969-2009). Int J Occup Environ Health 20:134-40.

van Zandwijk N, Reid G, Frank AL, 2020. Asbestos-related cancers: the 'Hidden Killer' remains a global threat. Expert Rev Anticancer Ther 20:271-8.

Vangelowa K, Dimitrova S, Dimitrova I, 2015. National asbestos profile of Bulgaria. Available from: https://ncpha.government.bg/ files/National\%20Asbestos\%20Profile_Bulgaria_2015-en.pdf Accessed: 3 January 2020.

Virta R, 2002. Asbestos: geology, mineralogy, mining, and uses. OpenFile Report 02-149. Available from: https://pubs.usgs. gov/of/2002/of02-149/ Accessed: 10 October 2015.

Virta R, 2006. Worldwide asbestos supply and consumption trends from 1900 through 2003. USGS Open-File Report 03-083. Available from: http://pubs.usgs.gov/circ/2006/1298/c1298.pdf Accessed: 10 October 2019.

Wagner JC, Sleggs CA, Marchand P, 1960. Diffuse pleural mesothelioma and asbestos exposure in the North Western Cape Province. Br J Ind Med 17:260-71.

Wakefield J, 2007. Disease mapping and spatial regression with count data. Biostatistics 8:158-83.

Wang Y, Yang Y, Shi X, Mao S, Shi N, Hui X, 2016. The spatial distribution pattern of human immunodeficiency virus/acquired immune deficiency syndrome in China. Geospat Health 11:414.

WHO, 2016. International statistical classification of diseases and related health problems - 10th revision. World Health Organization Geneva, Switzerland. Available from: http://apps.who.int/classifications/icd10/browse/2016/en Accessed: 20 October 2019.

WHO, 2018. Asbestos: elimination of asbestos-related disease. World Health Organization Geneva, Switzerland. Available from: http://www.who.int/news-room/fact-sheets/detail/asbestos-elimination-of-asbestos-related-diseases Accessed: 10 October 2019.

Wilk E, Krówczyńska M, Zagajewski B, 2019. Modelling the spatial distribution of asbestos-cement products in poland with the use of the random forest algorithm. Sustainability 11:4355.

Yang H, Testa JR, Carbone M, 2008. Mesothelioma epidemiology, carcinogenesis, and pathogenesis. Curr Treat Options Oncol 9:147-57. 